\title{
Alunos com deficiência auditiva e o ensino de Química: mapeamento da produção acadêmica nos SIMPEQUIs (2006-2021)
}

Students with hearing impairment and Chemistry teaching: mapping academic production in SIMPEQUIs (2006-2021)

Estudiantes con discapacidad auditiva y enseñanza de la Química: mapeo de la producción académica em SIMPEQUIs (2006-2021)

Luiz Guilherme Souza Fernandes Azevedo ORCID: https://orcid.org/0000-0003-1266-0359 Universidade Federal Fluminense, Brasil E-mail gasparsouza2510@gmail.com

Hosana Paiva da Costa

ORCID: https://orcid.org/0000-0002-0384-8184 Universidade Federal Fluminense, Brasil

E-mail: hosanapaivadacosta125@gmail.com

Ana Beatriz de Souza dos Santos ORCID: https://orcid.org/0000-0001-5337-6931 Universidade Federal Fluminense, Brasil E-mail: beatriz_ana@id.uff.br

Alice de Castro Bonadiman

ORCID: https://orcid.org/0000-0001-7003-2516 Universidade Federal Fluminense, Brasil E-mail: alicebonadiman2001@ gmail.com Eleonora Celli Carioca Arenare ORCID: https://orcid.org/0000-0002-6586-6257 Universidade Federal Fluminense, Brasil E-mail: eleonoracelliquímica@gmail.com

Marcelo Nocelle de Almeida

ORCID: https://orcid.org/0000-0003-3363-9217 Universidade Federal Fluminense, Brasil E-mail: mnocelle@id.uff.br

\begin{abstract}
Resumo
Esta pesquisa é resultante de reuniões ministradas para o curso de Graduação Licenciatura em Ciências Naturais envolvendo temáticas relacionadas ao Ensino de Química e a Educação Inclusiva, com destaque para a Deficiência Auditiva. O objetivo desta pesquisa foi mapear os trabalhos publicados nos SIMPEQUIs entre 2006 e 2021. A pesquisa teve caráter bibliográfico e procurou demonstrar para licenciandos a questão da Inclusão de alunos com limitações que cruzarão o percurso de sua história profissional. A metodologia utilizada foi a leitura dos registros publicados no evento escolhido, tendo por base os trabalhos publicados com tal temática e discussões realizadas durante o processo de Ensino de Química. Nossos resultados foram categorizamos em cinco partes: Concepções de professores e de alunos de Química; Utilização de simbologia usando LIBRAS, Trabalhos teóricos com referência ao Estado da Arte; Experimentação e Formação de Professores. Concluímos que existem fatores importantes, que interferem de forma significativa na associação, aprendizagem e inclusão de alunos com Deficiência Auditiva em aulas de Química: 1- Solicitação de um Intérprete de LIBRAS; 2- Materiais necessários para que o aluno surdo possa desenvolver habilidades de leitura e escrita; 3- Equipamento da sala de aula, com os recursos visuais; 4- A importância de uma educação inclusiva na formação inicial dos licenciados e a busca de uma formação continuada por professores de Química em relação ao objeto de estudo desta pesquisa; 5- Confecção de materiais de baixo custo pelos próprios alunos, no sentido de valorizar e motivar a turma em geral.
\end{abstract}

Palavras-chave: Aprendizagem; Pesquisa; Ensino de Química; Deficiência auditiva; SIMPEQUIs.

\section{Abstract}

This research is the result of meetings given for the Undergraduate Course in Natural Sciences involving themes related to Chemistry Teaching and Inclusive Education, with emphasis on Hearing Impairment. The objective of this research was to map the works published in SIMPEQUIs between 2006 and 2021. The research was bibliographical in nature and sought to demonstrate to undergraduates the issue of inclusion of students with limitations and who will 
cross the path of their professional history. The methodology used was the reading of the records published in the chosen event, based on published works with this theme and discussions carried out during the Chemistry Teaching process. Our results were categorized into five parts: Conceptions of chemistry teachers and students; Use of symbology using LIBRAS, Theoretical works with reference to the State of the Art; Experimentation and Teacher Training. We conclude that there are important factors that significantly interfere in the association, learning and inclusion of students with Hearing Impairment in Chemistry classes: 1- Request for a LIBRAS Interpreter; 2Materials necessary for the deaf student to develop reading and writing skills; 3- Classroom equipment, with visual resources; 4- The importance of inclusive education in the initial training of graduates and the search for continued training by Chemistry teachers in relation to the object of study of this research; 5- Preparation of low-cost materials by the students themselves, in order to value and motivate the class in general.

Keywords: Learning; Search; Chemistry teaching; Hearing deficiency; SIMPEQUIs.

\begin{abstract}
Resumen
Esta investigación es el resultado de las reuniones impartidas para la carrera de Licenciatura en Ciencias Naturales en temas relacionados con la Enseñanza de la Química y la Educación Inclusiva, con énfasis en la Discapacidad Auditiva. El objetivo de esta investigación fue mapear los trabajos publicados en SIMPEQUIs entre 2006 y 2021 . La investigación fue de carácter bibliográfico y buscó demostrar a los estudiantes el tema de la inclusión de estudiantes con limitaciones y que se cruzarán en el camino de su trayectoria profesional. La metodología utilizada fue la lectura de los registros publicados en el evento elegido, a partir de trabajos publicados con esta temática y discusiones realizadas durante el proceso de Enseñanza de la Química. Nuestros resultados se categorizaron en cinco partes: conceptos de profesores y estudiantes de química; Uso de simbología con LIBRAS, trabajos teóricos con referência al estado del arte; Experimentación y formación de profesores. Concluimos que existen factores importantes que interfieren significativamente en la asociación, aprendizaje e inclusión de estudiantes con Discapacidad Auditiva en las clases de Química: 1- Solicitud de Intérprete LIBRAS; 2- Materiales necesarios para que el estudiante sordo desarrolle sus habilidades de lectura y escritura; 3- Equipamiento del aula, con recursos visuales; 4- La importancia de la educación inclusiva en la formación inicial de los egresados y la búsqueda de la formación continua de los profesores de Química en relación con el objeto de estudio de esta investigación; 5- Elaboración de materiales de bajo costo por parte de los propios alumnos, con el fin de valorar y motivar a la clase en general.
\end{abstract}

Palabras clave: Aprendiendo; Buscar; Enseñanza de la Química; Pérdida de audición; SIMPEQUIs.

\title{
1. Introdução
}

A aprendizagem é um processo que depende e é influenciado por questões que estão muito além da pré-disposição que cada indivíduo tem em aprender. Não somente a condição prévia de cada indivíduo determina que tal processo aconteça, mas, o ambiente escolar também é um fator determinante.

Olhando pelo prisma tratado no parágrafo acima e se tratando do contexto da educação inclusiva autores como (Vandercook, Fleetham, Sinclair \& Tetlie, 1988, p. 19 apud Karagiannis, Stainback \& Stainback, 1999, p. 22) descrevem o ambiente de sala de aula como onde:

[...] "todas as crianças enriquecem-se por terem a oportunidade de aprender umas com as outras, desenvolvem-se para cuidar umas das outras e conquistam as atitudes, as habilidades e os valores necessários para nossas comunidades apoiarem a inclusão de todos os cidadãos”.

Voltando-se para a educação inclusiva de alunos com deficiência auditiva, a escola deve proporcionar um ambiente onde seu aluno tendo ou não tal deficiência, consiga aprender e se socializar com os outros indivíduos. Foi objetivando entender melhor como o assunto da educação inclusiva de alunos com deficiência auditiva, tem se desenvolvido dentro do contexto do ensino da química que nossa pesquisa se fundamentou.

Para isso, foi feito um mapeamento de registros de trabalhos publicados nos SIMPEQUIs (2006-2021) com relação a Inclusão de alunos com deficiência auditiva. Investigamos as publicações em relação tanto ao ensino, quanto a aprendizagem da química. Com o intuito de compreendermos as linhas de pensamento argumentativo que tais autores registram, em relação a essa temática em diferentes regiões brasileiras. 


\section{Referencial Teórico}

O ensino inclusivo de fato é uma área bastante abrangente onde diversas modalidades da educação podem atuar. Essa ideia é corroborada por Karagiannis et al. (1999), onde os autores descrevem que independente das características e particularidades de cada aluno, o ensino inclusivo pode ser definido como aquele que supre as suas necessidades. Camargo, Soffa e Markowicz (2017), complementam dizendo que a educação inclusiva além se caracterizar por esse múltiplo significado, ela não acontece simplesmente com a introdução de alunos com necessidades educacionais especiais dentro da sala de aula. Para que esses alunos sejam realmente incluídos as escolas regulares necessitam "de estratégias organizadas que possibilitem construir conhecimentos a partir de adaptações e adequações possíveis dentro da escola [...]”"

Existem muitas leis, decretos regulamentares, portarias e resoluções que garantem o direito da pessoa com deficiência. Merecem destaque a Constituição de 1988, a Lei $n^{\circ} 7.853 / 89$, o Decreto no 3.298/99 e a Lei ${ }^{\circ}$ 10.098/2000, que tratam dos direitos da pessoa com deficiência e sua inclusão de forma mais efetiva.

Recorrendo ao contexto histórico de publicações relacionadas a nossa temática de estudo, relacionados a décadas passadas, podemos observar que muitos pesquisadores e estudiosos se debruçaram sobre esta questão (World Health Organization, 2006b; Strobel, 2008; Daroque, 2011; Valetini \& Bisol, 2011; Carmozine \& Noronha, 2012; Fernandes, 2012; Kleina, 2012; Veloso \& Maia, 2012; Monteiro, Silva \& Hatner, 2013; Moura, 2016). Foram discutidas e debatidas por meio da divulgação científica explícita em seus trabalhos, questões que influenciam e abragem limitações com relação a evolução de processos cognitivos de alunos com Deficiência Auditiva. Assim como também professores se deparam em salas de aula com tais alunos com esta limitação corporal, salientando a importância do profissional "professor" em tal contexto.

A Deficiência Auditiva é um processo de limitação física na questão saúde de um ser humano. Com base nesta especificação, encontramos por meio da divulgação científica, a produção acadêmica de graduandos, licenciados, mestrandos, doutorandos, mestres, doutores, pesquisadores e professores que explanaram questões de saúde e questões educacionais, que influenciam tanto no processo de ensinar quanto de aprender determinados conteúdos. Dentre os inúmeros trabalhos que explanaram tal temática, nossa pesquisa traz um recorte da produção acadêmica sobre questões que se influenciam o ensinar e o aprender dos estabelece nos trabalhos publicados em duas temáticas:

1- Saúde e limitações do aluno e ou do professor com Deficiência Auditiva: Russo e Santos, 1993; Russo e Almeida, 1995; Passos (2004); WHO, 2006a; Galindo, 2007; Britto e Samperiz, 2010; Ossada e Rodrigues, 2016.

2- Estratégias, Métodos e Recursos usados para a aprendizagem de alunos com Deficiência Auditiva (Damázio, Alves \& Ferreira, 2010; Barreto \& Barreto, 2014; Mendes, Figueredo \& Ribeiro, 2015; Oliveira \& Benite, 2015; Abreu, 2016; Lopes 2017; Mendonça, Oliveira \& Benite, 2017; Silva \& Pimentel, 2019).

$\mathrm{Na}$ área de ensino de química, pesquisadores e estudiosos (Souza \& Silveira, 2011; Stadler, 2013; Ferreira \& Nascimento, 2014; Guedes, 2017; Vertuan \& Santos, 2019) tem publicados seus trabalhos com o intuito de colaborar para o aprimoramento das aulas de professores de Química. Soma-se ainda o intuito de mostrar que na lida diária de sala de aula encontraremos, durante nossa trajetória profissional, alunos com Deficiência Auditiva e que precisamos integrá-los dentro do contexto de estudo científico.

Mendonça et al. (2017) descreveram que algumas disciplinas, dentre elas a química, tem sua simbologia própria. Soma-se a isso a falta de formação por parte do docente voltada ao ensino de alunos surdos e a falta de formação científica por parte do intérprete na área das ciências. Esse conjunto de fatores acabam por impedir a interpretação dos conceitos científicos por parte dos alunos surdos.

As questões narradas acima influenciam e atrapalham o ensino da química para estes alunos. Ainda conforme (Ricardo, 2018, p. 155) “[...] a audição reduzida é uma deficiência física, que não atrapalha o desenvolvimento cognitivo. Com 
metodologias adequadas o aluno surdo pode ter as mesmas oportunidades", e o aprendizado do aluno com deficiência auditiva em grande parte é um resultado do trabalho conjunto entre professor do conteúdo e o intérprete em LIBRAS.

A partir de tal conhecimento, estabelecido pelas pesquisas em relação a temática, uma questão primordial que todo professor de Química poderia estabelecer com base em suas intencionalidades em ensinar tal ciência é: como eu, enquanto profissional, posso colaborar com a aprendizagem de alunos com tal limitação? Quantos alunos irão cruzar minha trajetória profissional em meu percurso diário percorrido anualmente em salas de aulas?

Baseados nessa argumentativa, nossa proposta de trabalho com relação a produção deste artigo, também é verificar de que forma os SIMPEQUIs, por meio das análises das publicações, como as pesquisas divulgadas tem contribuído para tal desafio. Que tipo de referencial argumentativo os professores de Química têm utilizado em sala de aula para enfrentar e estabelecer um fazer cotidiano mais comprometido com o processo de inclusão de alunos com deficiência auditiva?

\section{Metodologia}

A pesquisa descrita neste texto foi de natureza bibliográfica, tendo como corpus de análise o conjunto de trabalhos publicados nos anais do evento Simpósio Brasileiro de Educação Química - SIMPEQUI no período de 2006 a 2021. A busca pelos trabalhos foi realizada no domínio oficial desse evento e disponível na internet (www.abq.org.br/simpequi/edicoesanteriores.html). Para os anos de 2007, 2020 e 2021, o site não disponibilizou informações sobre o evento.

O referido evento foi escolhido por ser de grande relevância para a área de Ensino de Química no Brasil, sem desconsiderar que existem outros nos quais também se encontram produções relacionadas. Analisamos a produção acadêmica disponível no evento Simpósio de Pesquisa em Ensino de Química - SIMPEQUI, em seus respectivos locais e anos: Fortaleza - CE em 2008, Salvador - BA em 2009, Natal - RN em 2010, Natal - RN em 2011, Teresina - PI em 2012, Teresina - PI em 2013, Fortaleza - CE em 2014, Fortaleza - CE em 2015, Manaus - AM em 2016, Manaus - AM em 2017, Rio de Janeiro - RJ em 2018 e Modalidade Online em 2021.

A metodologia utilizada fundamentou-se na análise de conteúdo (Bardin, 2016), que é um método de tratamento e análise de dados qualitativos em que se procura encontrar convergências e incidências de palavras e frases. A análise de conteúdo segundo a autora é:

Um conjunto de técnicas de análise das comunicações visando obter, por procedimentos sistemáticos e objetivos de descrição do conteúdo das mensagens, indicadores (quantitativos ou não) que permitam a inferência de conhecimentos relativos às condições de produção/recepção (variáveis inferidas) destas mensagens (Bardin, 2011, p. 48).

Para a análise dos trabalhos analisamos na integra a presença de expressões e palavras relacionadas com o Ensino e Aprendizagem de Química para alunos com Deficiência Auditiva. Utilizamos os seguintes descritores na busca relacionada a nossa temática: ensino de química, aprendizagem em química, deficiência auditiva, LIBRAS, Língua brasileira de sinais, deficientes auditivos, surdez, surdos. Desta forma, para a escolha dos trabalhos incluídos em nossa pesquisa, levamos em conta expressões que se relacionavam a nossa temática, separamos por categorias, as quais foram emergindo a partir da análise de conteúdo, para identificação do número de publicações em cada categoria (conforme Tabela II).

A seguir serão apresentados os resultados e discussões relacionando a produção acadêmica com a deficiência auditiva e o ensino de química. A partir desta busca identificamos a produção acadêmica relacionada ao processo de Ensino e Aprendizagem de Química para alunos com Deficiência Visual, Região, UF e IES relacionados a publicação. (conforme a Tabela I). Foram categorizados em seis eixos temáticos, explanados na Tabela II: concepções de professores e de alunos de química; utilização de simbologia usando LIBRAS; utilização de materiais de baixo custo; trabalhos teóricos com referência ao estado da arte; formação de professores de química e experimentação. 


\section{Resultados e Discussão}

Foram identificados nesta pesquisa um total de 21 produções acadêmicas, que trazem um registro geral da forma como o processo de ensino e aprendizagem está se desenvolvendo para alunos com deficiência auditiva. Tais trabalhos relacionam-se por meio das seguintes palavras-chaves: "Ensino de Química”; "Deficiência Visual”; "Linguagem de Sinais"; "Comunicação Visual"; "Surdos"; "Deficientes Auditivos" e "Sinais".

Para termos um panorama sobre o registro dos trabalhos publicados nos SIMPEQUIs (2006-2021), em relação ao processo de ensino e aprendizagem inclusivo, envolvendo alunos com deficiência auditiva na ciência "química", listamos tais produções na Tabela 1:

Tabela 1 - Produção Acadêmica relacionada ao processo de Ensino e Aprendizagem de Química para alunos com Deficiência Visual, Região, UF e IES relacionados a publicação.

\begin{tabular}{|c|c|c|c|c|c|}
\hline SIMPEQUIs & ANO & TÍTULO & REGIÃO & IES & UF \\
\hline SIMPEQUI01 & 2006 & Aulas práticas de química para alunos surdos-mudos & Nordeste & UECE & $\mathrm{CE}$ \\
\hline SIMPEQUI02 & 2009 & $\begin{array}{l}\text { A sensibilização e a capacitação em LIBRAS, de acadêmicos de química } \\
\text { para um ensino adequado a alunos com deficiência auditiva }\end{array}$ & Norte & IFPA & PA \\
\hline SIMPEQUI03 & 2009 & $\begin{array}{l}\text { Uma nova metodologia de ensino de química para deficientes auditivos } \\
\text { do ensino fundamental }\left(8^{\mathrm{a}} \text { série }\right)\end{array}$ & Norte & IFPA & PA \\
\hline SIMPEQUI04 & 2011 & $\begin{array}{l}\text { Ensino de química aplicado a alunos surdos do } 9^{\circ} \text { ano da Escola } \\
\text { Governador Archer: uma interação mediada a linguagem de sinais e } \\
\text { outras formas de comunicação visual }\end{array}$ & Nordeste & UEMA & MA \\
\hline SIMPEQUI05 & 2012 & $\begin{array}{l}\text { A sinalização em Libras para o ensino de surdos na disciplina de química } \\
\text { em escolas regulares de Teresina-PI }\end{array}$ & Nordeste & UAPI & PI \\
\hline SIMPEQUI06 & 2012 & $\begin{array}{l}\text { Educação inclusiva e o ensino de química na Escola Estadual Professor } \\
\text { Camilo Dias }\end{array}$ & Norte & UERR & RR \\
\hline SIMPEQUI07 & 2013 & $\begin{array}{l}\text { Desafios do ensino de química para deficientes auditivos e visuais: } \\
\text { revisão de literatura }\end{array}$ & Nordeste & IFMA & MA \\
\hline SIMPEQUI08 & 2013 & $\begin{array}{l}\text { Limites e desafios na articulação dos conhecimentos científicos em uma } \\
\text { aula para estudantes surdos: o ensino do conceito de densidade }\end{array}$ & Sudeste & UFV & MG \\
\hline SIMPEQUI09 & 2013 & $\begin{array}{l}\text { A dificuldade do ensino de química orgânica para surdos: um estudo } \\
\text { exploratório }\end{array}$ & Sudeste & IFRJ & $\mathrm{RJ}$ \\
\hline SIMPEQUI10 & 2013 & $\begin{array}{l}\text { A disciplina de Libras: uma discussão com os alunos do curso de } \\
\text { Licenciatura em Química do IFPI }\end{array}$ & Nordeste & IFPI & PI \\
\hline SIMPEQUI11 & 2014 & $\begin{array}{l}\text { O Ensino de Língua Brasileira de Sinais - Libras no curso de } \\
\text { Licenciatura Plena em Química na modalidade a distância UAB/UFPI e } \\
\text { a inclusão do aluno surdo na Educação Básica }\end{array}$ & Nordeste & UFPI & PI \\
\hline SIMPEQUI12 & 2014 & $\begin{array}{l}\text { Utilização da Língua Brasileira de Sinais com alunos ouvintes do } \\
\text { Colégio Cefran }\end{array}$ & Nordeste & IFMA & MA \\
\hline SIMPEQUI13 & 2015 & $\begin{array}{l}\text { Concepções de estudantes surdos da Escola Estadual de Ouricuri/PE } \\
\text { sobre ciclo da água com adaptação em Libras }\end{array}$ & Nordeste & $\begin{array}{l}\text { IFSertão } \\
\text { PE }\end{array}$ & $\mathrm{PE}$ \\
\hline SIMPEQUI14 & 2015 & $\begin{array}{l}\text { Abordagem de conteúdos curriculares de química para alunos com } \\
\text { surdez: um estudo de caso em escolas públicas do estado do Ceará }\end{array}$ & Nordeste & UFC & $\mathrm{CE}$ \\
\hline SIMPEQUI15 & 2015 & A química através de imagens: ensino para discentes surdos & Nordeste & IFPB & PB \\
\hline SIMPEQUI16 & 2015 & O conceito de substância no ensino de química para surdos & $\begin{array}{c}\text { Centro- } \\
\text { Oeste } \\
\end{array}$ & UFG & GO \\
\hline SIMPEQUI17 & 2015 & $\begin{array}{l}\text { Avaliação do aprendizado de química utilizando a Língua Sinais } \\
\text { (LIBRAS) }\end{array}$ & Nordeste & UECE & $\mathrm{CE}$ \\
\hline SIMPEQUI18 & 2016 & $\begin{array}{l}\text { Recursos pedagógicos no ensino de química para estudantes surdos: o } \\
\text { que o SIMPEQUI, ENEQ e CBQ nos apresentam? }\end{array}$ & Norte & UEA & $\mathrm{AM}$ \\
\hline SIMPEQUI19 & 2016 & $\begin{array}{l}\text { Atendimento a alunos surdos do ensino médio integrado do Instituto } \\
\text { Federal do Amazonas - IFAM: apoio às atividades de biologia - química } \\
\text { - topografia e materiais de construção }\end{array}$ & Norte & IFAM & $\mathrm{AM}$ \\
\hline SIMPEQUI20 & 2017 & $\begin{array}{l}\text { Quinze anos da Lei de Libras: uma revisão dos estudos publicados nos } \\
\text { anais do Simpósio Brasileiro de Educação Química }\end{array}$ & Nordeste & IFBA & BA \\
\hline SIMPEQUI21 & 2017 & QUILIBRAS: sinais de uma boa reação & Nordeste & IFCE & CE \\
\hline
\end{tabular}

Fonte: Elaborada pelos autores (2021). 
Na produção acadêmica seis trabalhos foram identificados na região Nordeste o que correspondeu a 61,9\% do total, sendo, a maior parte no Ceará. A região Centro-Oeste registrou somente um trabalho, o que corresponde a 4,77\%. Enquanto na região Norte foram identificados quatro trabalhos (23,81\%). Por último, a região Sudeste destacou-se com 2 trabalhos $(9,52 \%)$. Não foi encontrado nenhum registro de trabalho nos SIMPEQUIs analisados envolvendo a temática deste estudo para a região Sul.

Com o propósito de mapear a produção acadêmica, identificamos as mesmas por meio de uma categorização evidenciada na Tabela 2.

Tabela 2 - Categorização dos Trabalhos analisados relacionados ao Ensino e a Aprendizagem em Química para alunos com Deficiência Visual.

\begin{tabular}{|c|c|c|}
\hline CATEGORIAS & FUNDAMENTAÇÃO & SIMPEQUIs \\
\hline $\begin{array}{lll}\text { Concepções } & \text { de } \\
\text { professores } & \text { e } & \text { de } \\
\text { alunos de química } & \end{array}$ & $\begin{array}{l}\text { Demonstram em geral como alunos e professores de química compreendem o processo de } \\
\text { ensino e aprendizagem em química, alguns relatam as dificuldades que permeiam tal } \\
\text { associação, as dificuldades encontradas no processo, algumas metodologias sobre seus } \\
\text { próprios pontos de vista são sugeridas e fazem uma avaliação em cima de uma aula ou prática } \\
\text { presenciada. }\end{array}$ & $\begin{array}{l}04 ; 05 ; 06 ; 09 \\
10 ; 13 ; 14 ; 15 \\
\quad 17 ; 19 ; 21\end{array}$ \\
\hline $\begin{array}{l}\text { Utilização de } \\
\text { simbologia usando } \\
\text { LIBRAS }\end{array}$ & $\begin{array}{l}\text { De forma geral, tais trabalhos trazem a importância do interprete de LIBRAS em aulas de } \\
\text { química, visto não existem sinais básicos relacionados aos conteúdos de química. }\end{array}$ & $\begin{array}{l}02 ; 04 ; 05 ; 06 \\
08 ; 09 ; 10 ; 11 ; \\
12 ; 13 ; 14 ; 15 \\
16 ; 17 ; 18 ; 19 \\
\quad 20 ; 21\end{array}$ \\
\hline $\begin{array}{l}\text { Trabalhos teóricos } \\
\text { com referência ao } \\
\text { Estado da Arte }\end{array}$ & $\begin{array}{l}\text { A relevância dos registros cotidianos da vida professoral aliado ao contexto histórico, são de } \\
\text { suma importância para o desenvolvimento e o aperfeiçoamento de novas pesquisas } \\
\text { relacionadas a temática }\end{array}$ & $07 ; 15 ; 18$ \\
\hline Experimentação & $\begin{array}{l}\text { Por meio da experimentação, ainda que sejam muitos as dificuldades que envolvem tal } \\
\text { processo em relação a inclusão dos alunos com deficiência auditiva no ensino de química, o } \\
\text { registro das pesquisas proporciona um ensino mais inclusivo onde a química, pode ser } \\
\text { compreendida como uma ciência para todos. }\end{array}$ & $\begin{array}{l}01 ; 03 ; 08 ; 13 ; \\
16 ; 21\end{array}$ \\
\hline $\begin{array}{l}\text { Formação de } \\
\text { Professores }\end{array}$ & $\begin{array}{l}\text { É inevitável a importância de uma formação inclusiva na formação dos licenciados e a busca } \\
\text { de uma formação continuada com professores de química em relação ao objeto de estudo desta } \\
\text { pesquisa. }\end{array}$ & $\begin{array}{l}02 ; 07 ; 08 ; 10 \\
11 ; 17 ; 20 ; 21\end{array}$ \\
\hline
\end{tabular}

Fonte: Elaborada pelos autores (2021).

Analisando as Tabelas 1 e 2 pode-se observar que a maioria dos trabalhos se encaixa em mais de uma categoria, principalmente, naquelas onde se destaca a utilização da simbologia usando LIBRAS. Apenas 14,28\% dos trabalhos não fazem referência a essa categorização, o que corresponde a um número pequeno de trabalhos, uma vez que, a LIBRAS é a base da comunicação entre surdos, deficientes auditivos e ouvintes.

Alguns trabalhos destacaram os olhares de professores e alunos com deficiência auditiva, a importância da noção de avaliação do contexto entre os envolvidos com a temática, massificando e identificando também conforme as pesquisas (Florentino, 2017; Rodrigues, Adams, Santos \& Eugênio, 2020) subsídios que auxiliem na construção do novo patamar evolutivo, frente aos trabalhos desenvolvidos no Brasil.

Por outro lado, grande parte dos trabalhos trouxeram a importância da utilização da linguagem de sinais em Libras, destacando as dificuldades encontradas no decorrer da ministração das aulas de química. Outros trabalhos (Oliveira, Reis, Gediel \& Catão, 2016; Perovano, Pontara \& Mendes, 2017) também salientaram como sendo desafios que devem ser superados pelos profissionais de Ensino de Química. Os autores citados acima sugerem o envolvimento de professores, alunos, familiares, gestores e coordenadores na adequação de processos inclusivos, programas governamentais que incentivem a inclusão. Ainda de acordo com esses autores, essa última questão é o fato primordial que consiste na formação inicial e continuada do grupo professoral. 
Os estudos desenvolvidos por meio de registros de estado da arte ou estado do conhecimento são de fundamental importância para o acompanhamento do que têm sido feitos na pesquisa, além de convergirem no sentido de ser fontes de apoio para o desenvolvimento de outras pesquisas, conforme trabalhos publicados que também abordam sobre a mesma temática (Vertuan \& Santos, 2019; Silva \& Dutra, 2020; Dantas, Barwaldt, Bastos \& Aragão, 2020).

As pesquisas concordam sobre a importância de uma reformulação no sentido atribuído a grafia visual, como uma responsabilidade dos professores visando tornar as aulas dinâmicas por meio de interações sociais e dialógicas que integrem os conteúdos da química, os conceitos científicos e a Linguagem de Sinais, por meio de atividades experimentais. Outros trabalhos corroboram essas afirmações anteriores enfatizando sobre a importância da formação dos professores e a ligação entre o professor de Química e o professor Intérprete em Libras, ambos no sentido de construção das práticas experimentais (Florentino, 2017; Mendonça et al., 2017; Silva \& Delfino, 2016; Rodrigues et al., 2020).

\section{Considerações Finais}

Se o professor souber compreender o progresso alcançado em cada um dos seus alunos estará contribuindo para solucionar e desmistificar os problemas de aprendizagem, eliminando ou minimizando a repetência, a evasão e as dificuldades de aprendizagem. Essas mudanças requerem novas atitudes em relação à compreensão de como se dá a aprendizagem dos alunos. Com base em nossas leituras relacionadas a temática, observamos que:

Para promover a inclusão, no caso da deficiência auditiva, a primeira atitude é a solicitação de um intérprete de Libras e materiais necessários para que o aluno surdo possa desenvolver habilidades de leitura e escrita. Qualquer escola que tiver alunos com deficiência auditiva nas classes regulares tem o direito à inclusão.

A inclusão escolar deve garantir a igualdade de acesso ao conhecimento a todos os alunos, inclusive aos que apresentam deficiências. Para isso é necessário equipar as salas com os recursos visuais, o que irá auxiliar o acesso do aluno. Ver as informações pode ajuda-los construir seu conhecimento de forma eficiente superando os entraves da surdez.

Escolas regulares de ensino que possuem alunos surdos matriculados devem obter recursos adequados para disponibilizá-los na sala de aula. A ausência desses recursos dificultará a aprendizagem dos alunos surdos. Outra questão fundamental para que o ensino e a aprendizagem dos alunos surdos ocorram com eficiência é participação do intérprete de LIBRAS. Esse profissional auxiliará os alunos surdos no sentido de acompanharem a aula simultaneamente com os alunos ouvintes.

É inevitável a importância de uma educação inclusiva na formação inicial dos licenciados e a busca de uma formação continuada com professores de química em relação ao objeto de estudo desta pesquisa. Outra questão importante é a confecção de materiais de baixo custo pelos próprios alunos, no sentido de valorizar e motivar a turma em geral. Sugere-se que esse material proporcione uma metodologia voltada para a experimentação.

De acordo com os trabalhos lidos, para sustentação teórica de nossa pesquisa, verificamos que muitas questões interferem na comunicação com alunos, professores ou mesmo com qualquer pessoa portadora de deficiência auditiva. Em nossa concepção, essas devem ser analisadas e discutidas nas salas de aulas das universidades brasileiras que possuem o curso de Licenciatura em Química. Dentre tais questões destacamos três abordagens essenciais, a serem discutidas e debatidas, durante o percurso da formação inicial: 1- Leituras sobre a temática em questão. Seria um dos primeiros passos para o professor de Química saber como contribuir para a inclusão de um aluno com Deficiência Auditiva em suas aulas. 2Expressões faciais e corporais corretas do professor de Química em sala de aula que possui algum aluno(a) com Deficiência Auditiva. 3- Elaboração de projetos, atividades e parcerias entre o intérprete com formação em Educação especial e o professor de Química. Essas atividades pedagógicas devem envolver a totalidade dos conteúdos curriculares da disciplina a serem 
desenvolvidos no decorrer do ano letivo. Esse propósito deve diversificar as aulas e promover o interesse e a motivação de todos os alunos da sala de aula no desenvolvimento de cada aula a ser ministrada.

Como sugestão para trabalhos futuros no evento SIMPEQUI, trazemos as seguintes sugestões: 1- Os autores fazerem uma busca do que tem sido publicado com a mesma temática em outros eventos na área de Ensino de Química; 2- Fazer a leitura de tais trabalhos para que certo conhecimento de informações se estabeleça em seus processos cognitivos. Assim, desta maneira poderá trazer novas sugestões em sua as futuras publicações, a partir do que já tem sido publicado em outros eventos brasileiros. 3- Estabelecer critérios apoiados em uma fundamentação teórica mais consistente, com o propósito de consolidar novos conhecimentos, estabelecidos por meio de seus próprios posicionamentos com relação a essa temática de estudo.

\section{Referências}

Abreu, M. C. B. F. (2016). A constituição de surdos em alunos no contexto escolar: conflitos, contradições e exclusões (Tese de Doutorado). Faculdade de Educação, Universidade Federal de Uberlândia, Uberlândia, MG, Brasil. https://repositorio.ufsc.br/bitstream/handle/123456789/188483/ABREU\%20M\%C3 $\%$ A1rcia\%20Cristina\%20Barreto\%20Fernandes\%20\%202016\%20\%28tese \%29\%20UFU.pdf?sequence=1\&isAllowed=y.

Bardin, L. (2016). Análise de Conteúdo. Edições 70.

Barreto, M. A., \& Barreto, F. O. C. (2014). Educação Inclusiva: contexto social e histórico, análise das deficiências e uso das tecnologias no processo de ensino-aprendizagem. Érica.

Britto, F. R., \& Samperiz, M. M. F. (2010). Dificuldades de comunicação e estratégias utilizadas pelos enfermeiros e sua equipe na assistência ao deficiente auditivo. Einstein, 8(1), 80-85.

Camargo, L. F., Soffa, M. M., \& Markowicz, D. (2017, setembro). Perspectivas sobre a educação inclusiva: um desafio possível. Congresso Nacional de Educação, Curitiba, Brasil, 11. https://educere.bruc.com.br/arquivo/pdf2017/23527_11750.pdf.

Carmozine, M. M., \& Noronha S. C. (2012). Surdez e LIBRAS: conhecimento em suas mãos. Hub Editorial.

Constituição da República Federativa do Brasil de 1988. http://www.planalto.gov.br/ccivil_03/Constituicao/Constituicao.htm

Damázio, M. F. M., Alves, C. B., \& Ferreira, J. P. (2010). A educação especial na perspectiva da inclusão escolar: abordagem bilíngue na escolarização de pessoas com surdez. Ministério da Educação, Secretaria de Educação Especial.

Dantas, L. M., Barwaldt, R., Bastos, A. R. B., \& Aragão, A. F. A. (2020). Análise das produções científicas acerca de recursos pedagógicos acessíveis da tabela periódica utilizados no processo de ensino e aprendizagem de alunos surdos. Revista Educação Especial, 33, 1-28. https://periodicos.ufsm.br/educacaoespecial/article/view/48149/html.

Daroque, S. C. (2011). Alunos Surdos no Ensino Superior: uma discussão necessária (Dissertação de Mestrado). Universidade Metodista de Piracicaba, Piracicaba, SP, Brasil. https://www.metodista.br/revistas/revistas-unimep/index.php/comunicacoes/article/view/1534/1088.

Decreto n. 3.298, de 20 de dezembro de 1999. Regulamenta a Lei n. 7.853 de 24 de outubro de 1989, dispõe sobre a Política Nacional para a Integração da Pessoa Portadora de Deficiência, consolida as normas, e dá outras providências. https://www.planalto.gov.br/ccivil_03/decreto/D3298.htm.

Fernandes, S. F.P. (2012). A formação de professores de ciências biológicas e a educação inclusiva: uma interface da formação inicial e continuada. (Dissertação de Mestrado). Universidade Federal de Goiás, Goiânia, GO, Brasil.

Ferreira, W. M., \& Nascimento, S. P. F. (2014). Utilização do jogo de tabuleiro - ludo - no processo de avaliação da aprendizagem de alunos surdos. Química Nova na Escola, 36(1), 28-36.

Florentino, C. P. A. (2017). Análise de uma sequência de ensino investigativa no ensino de química realizada com um grupo de estudantes surdos (Dissertação de Mestrado). Instituto Federal de Educação, Ciência e Tecnologia de São Paulo. São Paulo, SP, Brasil. https://spo.ifsp.edu.br/images/phocadownload/DOCUMENTOS_MENU_LATERAL_FIXO/POS_GRADUA\%C3\%87\%C3\%83O/MESTRADO/Ensino_de_C i\%C3\%AAncias_e_Matem\%C3\%A1tica/Dissertacoes/2017/Disserta\%C3\%A7\%C3\%A3o_Carla_Araujo_Florentino.pdf.

Galindo, C. A surdez súbita. http://www.drashirleydecampos.com.br/noticias/12670.

Guedes, C. T. (2017). Ensino de Química em Libras: uma análise crítica. (Trabalho de conclusão de curso). Universidade Federal Fluminense, Niterói, RJ, Brasil.

Karagianis, A., Stainback, W., \& Stainback, S. (1999). Fundamentos do Ensino Inclusivo. In: Stainback, S. \& Stainback, W. Inclusão: um guia para educadores (cap. 1, pp. 21-34). Tradução de Magda França Lopes. Porto Alegre: Artmed Editora S.A. https://staticsshoptime.b2w.io/sherlock/books/firstChapter/176426.pdf.

Kleina, C. (2012). Tecnologia assistiva em educação especial e educação inclusiva. InterSaberes.

Lei n. 7853, de 24 de outubro de 1989. Dispõe sobre o apoio às pessoas portadoras de deficiência, sua integração social, sobre a Coordenadoria Nacional para Integração da Pessoa Portadora de Deficiência - Corde, institui a tutela jurisdicional de interesses coletivos ou difusos dessas pessoas, disciplina a atuação do Ministério Público, define crimes, e dá outras providências. http://www.planalto.gov.br/ccivil/LEIS/L7853.htm. 
Lei n. 10.098, de 19 de dezembro de 2000. Estabelece normas gerais e critérios básicos para a promoção da acessibilidade das pessoas portadoras de deficiência ou com mobilidade reduzida, e dá outras providências. http://www.planalto.gov.br/ccivil/LEIS/L10098.htm.

Lopes, G. K. F. (2017). O uso das tecnologias no processo de ensino e de aprendizagem do surdo: Libras em educação à distância. Revista Virtual de Cultura Surda, 20, 1-29. https://editora-arara-azul.com.br/site/admin/ckfinder/userfiles/files/2\%C2\%BA\%20Artigo\%20de\%20Gerison\%20Kezio\%20Fernandes \%20Lopes.pdf.

Maia, V., \& Veloso, E. (2012). Aprenda LIBRAS com eficiência e rapidez. (7a ed.), Editora Mão Sinais.

Mendes, A. Q. S., Figueredo, F., Ribeiro, A. C. (2015). Inclusão de alunos surdos na escola regular: aspectos linguísticos e pedagógicos. Revista de Iniciação Cientifica, 2(2), 33-46. https://www.cairu.br/riccairu/pdf/artigos/2/03_INCLUSAO_ALUNOS_SURDOS.pdf.

Mendonça, L. M., Carvalho, T. W., Domingues, L. S., Faria, A. C. C. (2018). A importância da LIBRAS como componente curricular na educação básica. Educação: Saberes e Prática, 7(1), 1-14. http://revistas.icesp.br/index.php/SaberesPratica/article/viewFile/342/238.

Mendonça, N. C. S., Oliveira, A. P., \& Benite, A. M. C. (2017). O Ensino de Química para alunos surdos: o conceito de misturas no Ensino de Ciências. São Paulo. Química Nova na Escola, 39(4), 347-355. http://qnesc.sbq.org.br/online/qnesc39_4/07-RSA-88-16.pdf.

Monteiro, R., Silva, D.N.H., Ratner, C. (2013). Surdez e diagnóstico: narrativas de surdos adultos. Psicologia: teoria e pesquisa, 32(esp), 1-7

Moura, A. F. (2016). Acesso ao ensino superior: a experiência do aluno surdo no ensino médio. (Dissertação de Mestrado). Faculdade de Ciências, Universidade Estadual Paulista Júlio de Mesquita Filho. Bauru, SP, Brasil. http://projetoredes.org/wp/wp-content/uploads/moura_af_me_bauru.pdf.

Oliveira, C. L. R., Reis, I. F., Gediel, A.L.B., \& Catão, V. (2016). Experiências vivenciadas em contextos não escolares e o uso de libras na educação dos surdos: o ensino da química tendo como foco a inclusão dos surdos. Experiências em Ensino de Ciências, 11(2), 11-25. https://fisica.ufmt.br/eenciojs/index.php/eenci/article/view/555/526.

Oliveira, W. D., \& Benite, A. M. C. (2015). Estudos sobre a relação entre o intérprete de LIBRAS e o professor: implicações para o ensino de ciências. Revista Brasileira de Pesquisa em Educação em Ciências, 15(3), 597-626. https://periodicos.ufmg.br/index.php/rbpec/article/view/4331

Ossada, S.A.R., \& Rodrigues, S.C.M. (2015). A Tecnologia da Informação em colaboração na comunicação dos deficientes auditivos. FASCH-Tech, 1, 48-59.

Passos, O. (2004, setembro). Interdisciplinaridade e surdez. Congresso Internacional, 3 e Seminário Nacional do Instituto Nacional de Educação de Surdos, 9. Rio de Janeiro, Brasil. Educação de surdos: múltiplas faces do cotidiano escolar. Anais. Rio de Janeiro: Instituto Nacional de Educação de Surdos, 2004. p. 142.

Perovano, L. P., Pontara, A. B., \& Mendes, A. N. F. (2017). Dominó inorgânico: uma forma inclusiva e lúdica para o ensino de química. Revista Conhecimento Online, 2(9), 37-50. https://periodicos.feevale.br/seer/index.php/revistaconhecimentoonline/article/view/1088/1831.

Ricardo, F. S. V. (2018). A importância da inclusão de aluno com deficiência auditiva na escola de ensino regular de Naviraí/MS: um estudo de caso. Revista Científica Multidisciplinar Núcleo do Conhecimento, 3(12), 153-169. https://www.nucleodoconhecimento.com.br/pedagogia/aluno-com-deficiencia-auditiva.

Rodrigues, R. P., Adams, F. W., Santos, J. S. B., \& Eugênio, J. L. G. (2020). A relação entre professores de química e intérprete de libras no curso profissionalizante de uma escola do município de Itumbiara- GO. Revista Práxis, 12(23), 119-126. https://moodleead.unifoa.edu.br/revistas/index.php/praxis/article/view/3011/2624.

Russo, I. C. P., \& Santos, T. M. M. (1993). A prática da audiologia clínica. (4a. ed.), Cortez.

Russo, I. C. P., \& Almeida, K. (1995). O processo de reabilitação audiológica do deficiente auditivo idoso. In: Marchesan, I. Q. (Org.). Tópicos em fonoaudiologia (pp. 429-446). Lovise.

Silva, E. R. A. S., \& Delfino, J. R. (2016). Reflexão sobre o emprego de estratégias lúdicas no ensino de química para alunos surdos do ensino médio regular. Acta Tecnológica, 11(2), 87-98. https://portaldeperiodicos.ifma.edu.br/index.php/actatecnologica/article/view/412/280.

Silva, J. C., \& Dutra, M. M. (2020). Ensino de química no contexto da educação especial: uma análise de artigos publicados na revista química nova na escola no período de 1995 a 2016. Revista Prática Docente, 5(1), 431-448. http://periodicos.cfs.ifmt.edu.br/periodicos/index.php/rpd/article/view/642/279.

Silva, R. D., \& Pimentel, M. D. C. P. (2019). O ensino da Geografia e a educação especial e inclusiva: análise da metodologia aplicada a alunos com deficiência auditiva do ensino fundamental da escola estadual Prof. ${ }^{\text {a }}$ Coema Souto Maior Nogueira na Cidade de Boa Vista/RR. Ambiente: Gestão $e$ Desenvolvimento, 12(3), 22-32. https://periodicos.uerr.edu.br/index.php/ambiente/article/view/353.

Souza, S. F., \& Silveira, H. E. (2011). Terminologias químicas em libras: a utilização de sinais na aprendizagem de alunos surdos. Revista Química Nova na Escola. 33(1), 37-46. http://qnesc.sbq.org.br/online/qnesc33_1/06-PE6709.pdf.

Stadler. J. P. (2013). Ensino bilíngue libras/português para alunos surdos: investigação dos cenários da educação bilíngue de química e de sinais específicos em sala de aula (Trabalho de conclusão de curso). Universidade Tecnológica Federal do Paraná. Curitiba, PR, Brasil.

Strobel, K.L. (2008). As imagens do outro sobre a cultura surda. Editora UFSC.

Valentini, C. B., Bisol, C. A., \& Matos, S. R. L. (2017). Perspectivas críticas em educação especial e educação inclusiva. In: Pacheco, J. A., Mendes, G. L., Seabra, F., \& Viana, I. C. (Org.). Currículo, Inclusão e Educação escolar (pp. 734-742).: Universidade do Minho.

Vertuan, G. S., \& Santos. L. F. (2019). O ensino de química para alunos surdos: uma revisão sistemática. Revista Educação Especial, 32, 1-20. https://periodicos.ufsm.br/educacaoespecial/article/view/31242/31242.

World Health Organization. (2006a). Grades of hearing impairment. http://www.who.int/pbd/deafness/hearing_impairment_grades/en/print.html.

World Health Organization. (2006b). Prevencion of deafness and hearing impairment. http://www.who.int/pbd/deafness/hearing_impai rment_grades/en/print.html. 